Review

\title{
Investigating germination and outgrowth of bacterial spores at several scales
}

\author{
Clément Trunet ${ }^{\mathrm{a}, \mathrm{b}}$, Frédéric Carlin ${ }^{\mathrm{c}}$, Louis Coroller ${ }^{\mathrm{a},{ }^{*}}$ \\ a Université de Brest, EA3882, Laboratoire Universitaire de Biodiversité et Ecologie Microbienne, UMT14.01 SPORE-RISK, ISBAM, 6 Rue de l'Université, F- \\ 29334 Quimper, France \\ ${ }^{\mathrm{b}}$ ADRIA Développement, UMT14.01 SPORE-RISK, Z.A. de Creac'h Gwen, Quimper, France \\ ' UMR408 SQPOV “Sécurité et Qualité des Produits d'Origine Végétale", INRA, Avignon Université, 84000 Avignon, France
}

Keywords:

Spore-forming bacteria

Bacillus

Cellular analysis

Molecular analysis

Single cell

Flow cytometry

'Omics'

Microscopy

\begin{abstract}
A B S T R A C T
Background: Spore-forming bacteria are a major cause of food spoilage and food poisoning. Spores that resist physical and chemical treatments used in the food industry may germinate and multiply. Spore germination, outgrowth and growth constitute a complex and highly heterogeneous process. Scope and approach: Various techniques and methods can be used to observe the germination, outgrowth and early multiplication process of spore-forming bacteria and/or to quantify the impact of environmental conditions on its progress over time within a spore population. These techniques can be classified by different criteria: (i) the scale of analysis, from populations or cells to molecules, and (ii) the number of analyzed objects (cells) and (iii) the potential of the method to describe and/or quantify the impact of lethal or sub-lethal treatments or environmental conditions. Such treatments are applied to a spore population or a single spore and take into account parameters at the cellular level (growth capacity, morphological properties) to molecular level (proteomics, transcriptomics, spore molecular composition).

Key findings and conclusion: A better understanding and quantification of the germination, outgrowth and growth process require the implementation of several complementary methods. Methods providing information at single and population levels, as well as at molecular and cellular levels, are essential to assess and control the fate of spore-forming bacteria development in food systems.
\end{abstract}

\section{Introduction}

Spore-forming bacteria are largely studied in fundamental research on Gram-positive bacteria and for the numerous industrial applications of the spores themselves, of their enzymes and of their metabolites. Spores of Bacilli or Clostridia can remain dormant for years and have a much greater resistance to very diverse physical and chemical agents than their vegetative cells. After germination and multiplication, they can be responsible for food poisoning and food spoilage (Mallozzi, Viswanathan, \& Vedantam, 2010; Setlow, 2014; Wells-Bennik et al., 2016). Recovery after chemical or physical stress is a complex phenomenon comprising the germination of

* Corresponding author. Laboratoire Universitaire de Biodiversité et Ecologie Microbienne, Unité Mixte Technologique SPORE-RISK, Ecole Supérieure d'Ingénieurs en Agroalimentaire de Bretagne atlantique, 2, rue de l'Université, 29334 Quimper cedex, France.

E-mail address: louis.coroller@univ-brest.fr (L. Coroller). spores, the restoration of metabolic activity in suboptimal or favorable conditions and the emergence of the first vegetative cell able to multiply (Setlow, 2013). Germination, outgrowth and growth are characterized by a high variability of the behavior of individual cells. This variability is, moreover, highly influenced by environmental conditions. Monitoring the germination and growth of bacterial spores meets two major objectives: (i) to obtain a better understanding of a major physiological process of cell differentiation in the microbial world and (ii) to implement a quantitative evaluation of the impacts of physical and chemical treatments and/ or of environmental conditions on the ability of spores to germinate and grow, and hence become a troublemaker for public health, food production and distribution, and other industrial activities.

This review provides a description of the different techniques and methods for monitoring spore germination and growth after exposure to sublethal treatments and/or suboptimal environments. The discussion focuses on the information provided by different investigation methods with regards to the scales of examination 
(from cell to molecules, from populations to single cells, from millions to dozens of single events) and their potential for describing and/or quantifying the impact of treatment or environmental conditions.

\section{Overview of spore germination and characterization of spore properties}

Germination encompasses the deep morphological and physiological modifications of dormant spores to become vegetative cells. The physiological stages observed during germination and growth can be defined by criteria linked to the changes in spore properties. At first, refractivity loss is due to the rehydration of the spore core. Then, the size of the cell increases as the spore converts to a rod-shaped vegetative cell during the germination, outgrowth and growth process. Simultaneously the respiratory activity is restored, the membranes become fluid and the resistance to wet heat is lost. At a molecular level the CaDPA which was accumulated during sporulation, maintaining low water content in the spore core, is released and RNA expression and protein and other (macro) molecule synthesis starts again (Setlow, 2014). These physiological and molecular events may be used to differentiate dormant and germinated spores, or outgrowing and vegetative cells during the germination, outgrowth and growth process (Fig. 1).

The term "germinant" designates nutrient and non-nutrient factors triggering spore germination (Setlow, 2003). Nutrient germinants are low molecular weight compounds including, but not restricted to, amino acids, sugars and purine nucleosides possibly acting in combination and whose effects can be reinforced by cogerminants such as cations. Non-nutrient germinants include the dipicolinic acid-calcium complex (CaDPA, specific to spore-forming bacteria) or high hydrostatic pressure (Setlow, 2013). Germination leads to the rehydration of the spore and the release of the CaDPA concentrated in the spore core. Then, the cortex is hydrolyzed by cortex lytic enzymes (CLEs) such as SleB and CwlJ, the two major CLEs in Bacillus sp. Cortex hydrolysis allows the core to expand and complete rehydration to approximately $80 \%$ of spore weight (Setlow, 2014). Spores lose their high resistance to moist heat and chemicals early after core hydration. The spore becomes permeable as the inner-membrane surrounding the core expands. In the dormant stage, the low inner membrane permeability prevents small molecules from penetrating the core (Sunde, Setlow, Hederstedt, \& Halle, 2009). Finally, the hydration of the spore and the release of CaDPA lead to the loss of spore refractivity (Fig. 1). Metabolic activity and macromolecule synthesis are restored during outgrowth. The spores swell up and escape from the outermost layers, the proteinaceous coat and exosporium (Abee et al., 2011). This step leads to the formation of a new vegetative cell able to multiply. The transformation of a germinated spore into a vegetative cell is characterized by morphological changes: the cell size increases, the new cell comes out of the coat and exosporium, and the restoration of a metabolic activity marks a deep physiological modification (Pandey et al., 2013). The shifts from dormant spores to germinated spores, then from germinated spores to vegetative cells are highly heterogeneous (Setlow, 2012). This variability can be the result of differences in the expression of genes governing sporulation and/or environmental conditions among the population of cells during sporulation as the germination and outgrowth behavior depends on the molecular reserves produced during spore formation. This variability results in different spore dehydration rates, different amounts of enzymes involved in germination and a different number of germinant receptors which are put in place during sporulation (Chastanet et al., 2010; Setlow, 2014). This variability in turn affects heat resistance, germination and growth ability (Hornstra, de Vries, Wells-Bennik, de Vos, \& Abee, 2006;
Setlow, 2013).

The study of physical and/or physiological spore transformations requires different levels of analysis, and thus different observation and quantitative methods. Monitoring germination and outgrowth consists in following characteristics which are representative of the spore transformation, over time and within a given spore population. The previously described spore transformations are quantifiable criteria for distinguishing the successive physiological stages of spores during germination and growth. These changes can be observed in populations as well as in individual spores using different techniques and methods, providing information on cellular behavior as well as on molecular characteristics (Fig. 2A-B). Flow cytometry and microscopy methods examine sub-populations and single cells at cellular or molecular levels (Fig. 2C-D). Molecular methods apply to populations or single cells giving information at genomic, transcriptomic, proteomic or other molecular levels (Fig. 2E-F-G).

\section{Culture dependent methods and indirect measurements} (Fig. 2A-B)

Cultural methods require media (broth or solid) containing the necessary elements to provide spore germination, outgrowth and cell multiplication (Fig. 2A). Cells forming a colony on agar plates have definitely experienced germination, outgrowth and multiplication. The detection threshold is 10 to $10^{2}$ spores $\mathrm{CFU} \mathrm{mL} \mathrm{mL}^{-1}$ and can be continued with the dilution procedure. The sensitivity is high as the presence of a few spores can be detected among populations of a million or even billion cells that can be eliminated by a moderate heat treatment or by exposure to an ethanol solution. Culture dependent methods have been applied to estimate the impact of sporulation conditions, the intensity of heat treatment and the recovery environment on the ability of spores to form a colony on agar plates, particularly after a heat process. More generally they can be used to quantitatively assess growth, survival or recovery in laboratory media or in real foods after physical or chemical treatments of the spore-forming bacteria of concern. These data are used to develop mathematical models predicting bacterial behavior to optimize, control and improve food quality and safety (Baril et al., 2012; Leguerinel, Couvert, \& Mafart, 2000; Leguérinel, Couvert, \& Mafart, 2006; Mafart \& Leguérinel, 1998; Mtimet et al., 2015; Trunet et al., 2015).

Germination is characterized by the rehydration of spores, revealed by the transformation of spores from phase-bright to dark-phase (Fig. 2B). This corresponds to a decrease in the $A_{600}$ of spore suspensions, necessarily at relatively high concentrations (i.e. $10^{7}-10^{8}$ spore $/ \mathrm{ml}$ ) to exceed the detection limit of spectrophotometric measurements. For example the impact of suboptimal sporulation and incubation conditions on the germination of $B$. weihenstephanensis or of $B$. cereus has been evaluated by monitoring changes in $A_{600}$ of spore suspensions (Garcia, van der Voort, \& Abee, 2010; van Melis, Almeida, Kort, Groot, \& Abee, 2012). A 62\% decrease in initial $A_{600}$ for Bacillus weihenstephanensis or a $45 \%$ decrease for $B$. cereus corresponded to a $99.9 \%$ germination rate. Unsurprisingly, spectrometric methods do not involve direct observation of spores and therefore do not allow any assessment of the variability in individual cell behaviors. Moreover, these techniques can only be applied to transparent liquids.

Furthermore, by studying changes in absorbance of a spore suspension, the shift from a dormant spore to a vegetative cell able to multiply can also be examined. Vegetative cell multiplication leads to an increase in $A_{600}$ with the increase in turbidity. Monitoring the evolution of $A_{600}$ allows to estimate the lag time corresponding to the time to first cell division, encompassing the germination time and the time needed for growth. With this 

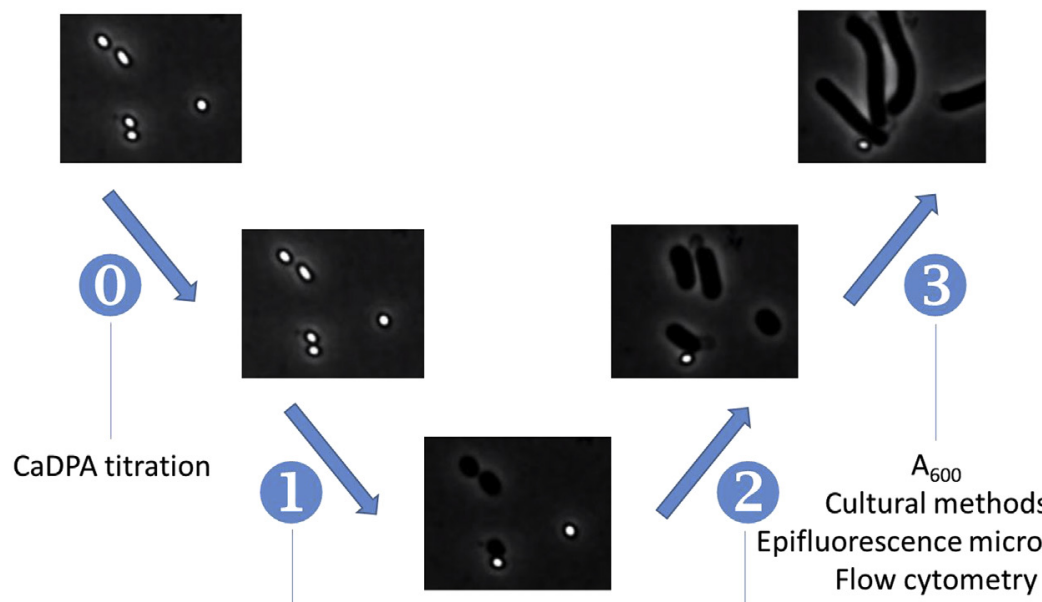

Cultural methods

Epifluorescence microscopy

Flow cytometry

'omics'

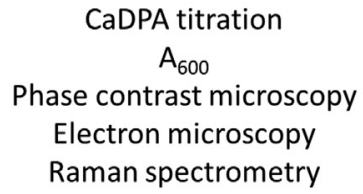

Phase contrast microscopy

Epifluorescence microscopy

Electron microscopy

Electron microscopy

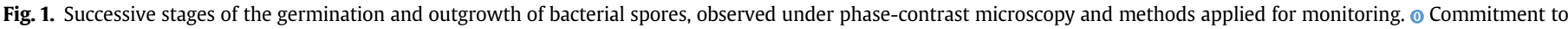

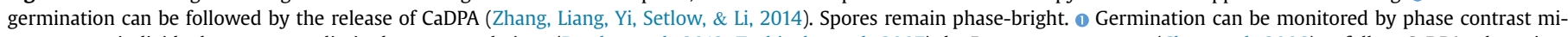

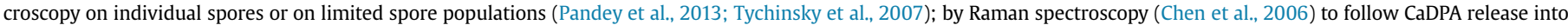

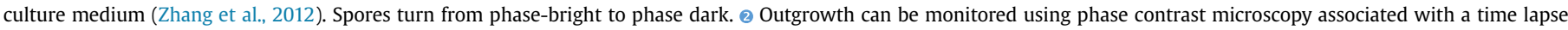

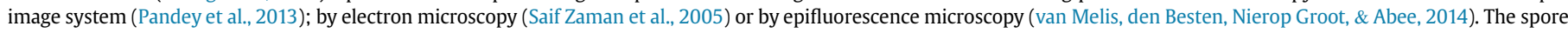

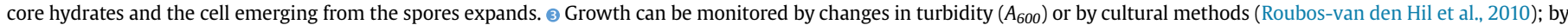

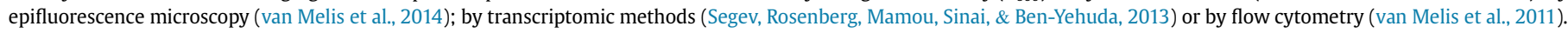
Rod-shaped cells divide and multiply.

method, a prolonged germination and lag phase and a lower germination rate were observed with spores produced in suboptimal sporulation conditions, then heat-treated or incubated in suboptimal conditions (Collado, Fernández, Rodrigo, Camats, \& Lopez, 2003; Daelman et al., 2013; Gaillard, Leguérinel, Savy, \& Mafart, 2005; Roubos-van den Hil, Dalmas, Nout, \& Abee, 2010). Using modern microplate readers that can be set to a wide range of incubation temperatures, culture conditions are miniaturized in microwells and $A_{600}$ readings are automated and finally computed. A large number of data are potentially generated and the influence of a large number of variable factors on inactivation, germination and spore incubation can be tested. This method is not very indicative for the quantification of the number of germinating spores that give rise to multiplying vegetative cells. An increase in $A_{600}$ can be due to anything from one to millions of spores, the only difference being in the time to a measurable change in $A_{600}$. Moreover the heterogeneity within the cell population is not observable. As $A_{600}$ reading is also poorly sensitive and does not discriminate cells from other materials, monitoring germination by spectrometry uses highly concentrated spore suspensions (about $10^{7}$ spore $/ \mathrm{ml}$ ) and therefore requires the preparation of high amounts of clean debris-free spore suspensions. However single spores can be isolated in microplate wells by limit dilution techniques or sorted by flow cytometry (Smelt, Bos, Kort, \& Brul, 2008; Stringer, Webb, \& Peck, 2011) (Fig. 2B). By monitoring $A_{600}$ in cultures formed from these isolated cells over time, the times to spore germination and first cell division from single spores can be estimated. A shorter lag time and a lower variability of the lag time of heat-activated Bacillus subtilis and Clostridium botulinum spores were revealed (Smelt et al., 2008; Stringer, Webb, George, Pin, \& Peck, 2005). The variability in lag times depends on sporulation conditions, on the intensity of the inactivation treatment by heat and on the incubation conditions (Garcia et al., 2010; Smelt et al., 2008; Stringer et al., 2011).

Germination can also be monitored by studying the changes in the concentration of CaDPA in the incubation medium (Fig. 2B) that corresponds to its release concomitant with the hydration to the spore core. Several methods are available for DPA assay. One for instance uses the photoluminescence of DPA in the presence of terbium. The complex Tb-DPA is excited at $270 \mathrm{~nm}$ and the emitted fluorescence wavelength is $545 \mathrm{~nm}$. The concentration in the released DPA is maximal when the germination of the spore population is completed. The relative DPA release at time $t$ is calculated as the ratio between $R F U$ at $t$ and maximum RFU at full germination (Yi \& Setlow, 2010; Zhang, Thomas, Li, \& Setlow, 2012). By monitoring the DPA release, early events such as "commitment" and germination can be studied or the impact of heat treatment on germination time quantified (Kort et al., 2005; Paidhungat et al., 2002).

The bioluminescence of spores of engineered strains containing the lux gene (Fig. 2B) has also been exploited. Particularly, the lux gene was under the control of specific promoters, such as the $\operatorname{ssp} B$ promoter. The $s s p B$ gene codes for a small acid-soluble protein (SASP) found in the spore core. As the spore germinates, the core is hydrated and the spores emit bioluminescence almost instantaneously as the intact luciferase, packaged during sporulation, leads to light emission. Relative Light Units are measured over time to evaluate the percentage of germinated spores within the population (Ciarciaglini et al., 2000; Hill et al., 1994). This method was notably used to quantify the impact of mild acidity, lactic acid and pasteurization on the germination of $B$. subtilis spores or to study the first steps in the germination process of Bacillus subtilis with different genetic backgrounds (Ciarciaglini et al., 2000; Setlow, Melly, \& Setlow, 2001). Difficulty in strain transformation, 
Version définitive du manuscrit publiée dans / Final version of the manuscript published in :

Trends in Food Science \& Technology (2017), Vol. 64, p. 60-68, DOI: 10.1016/j.tifs.2017.03.008

Journal homepage : http://www.journals.elsevier.com/locate/trends-in-food-science-and-technology

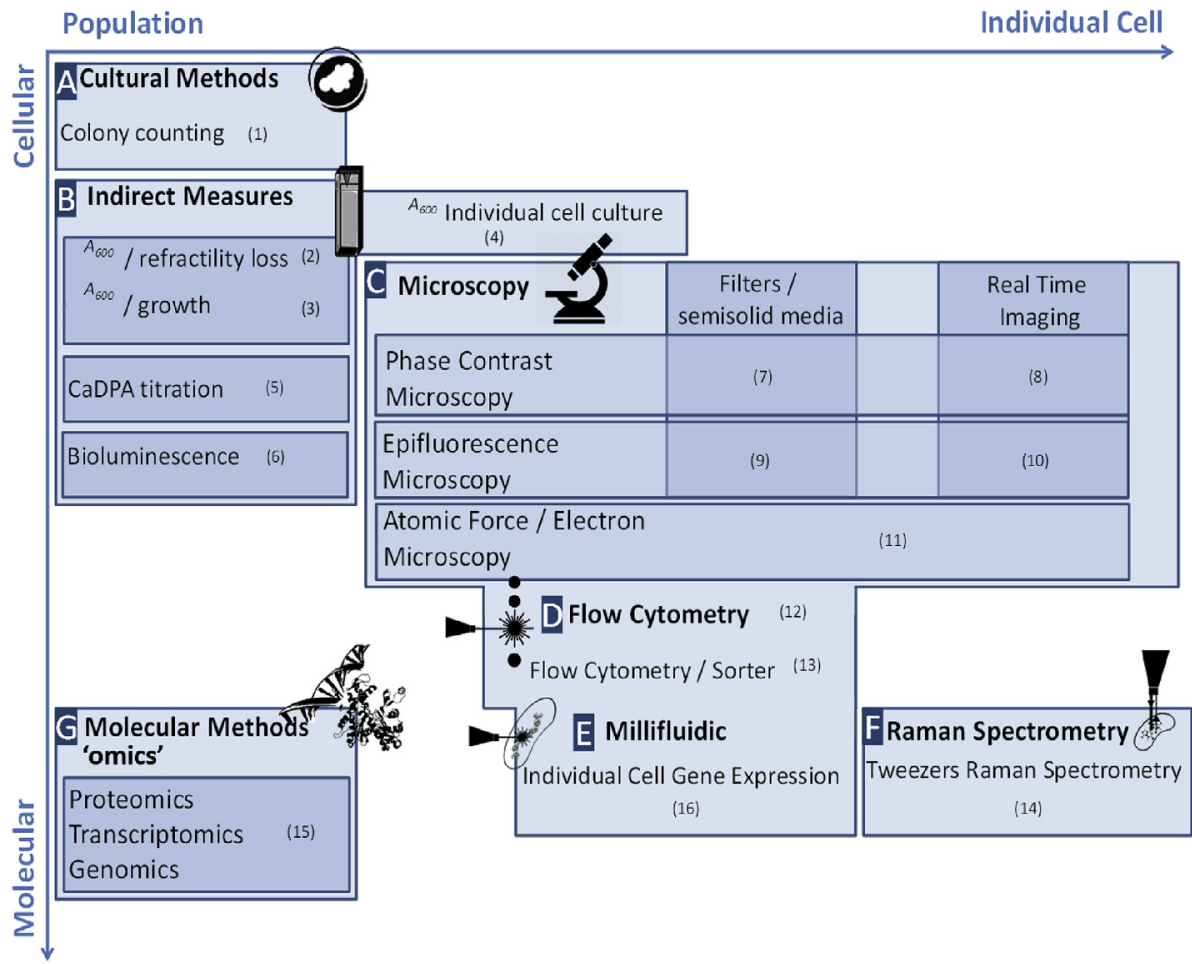

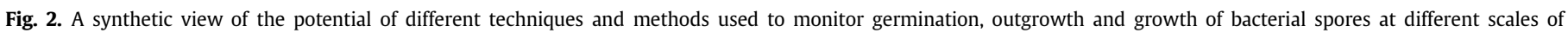

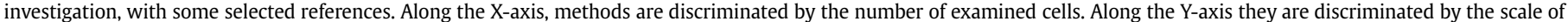

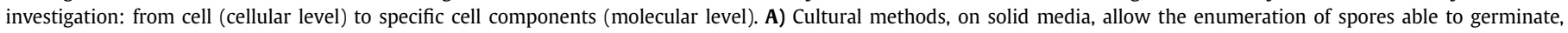

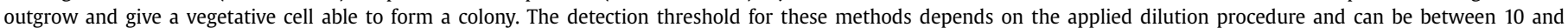

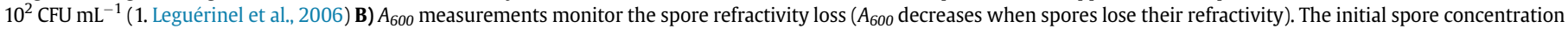

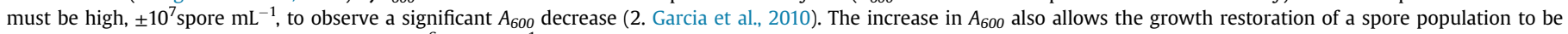

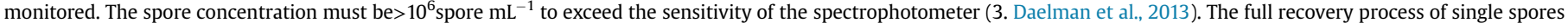

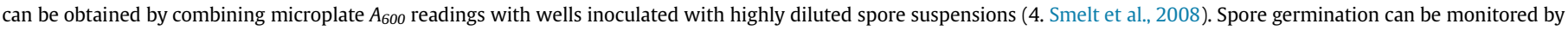

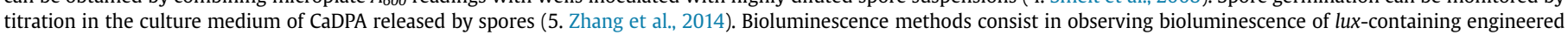

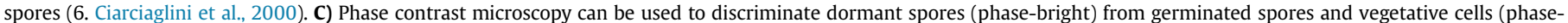

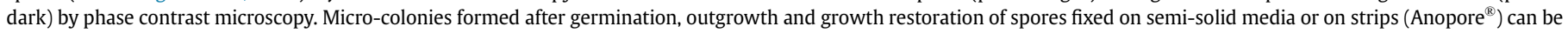

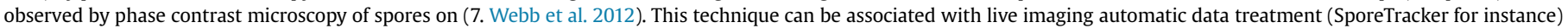

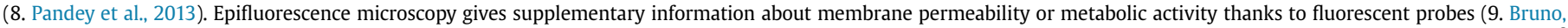

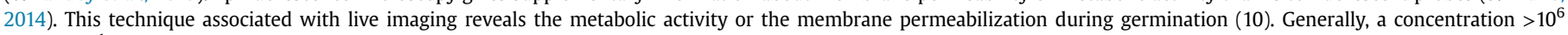

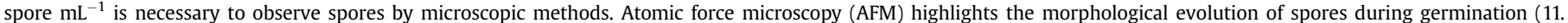

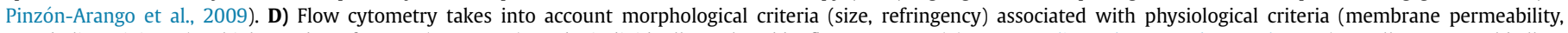

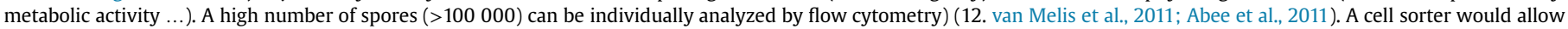

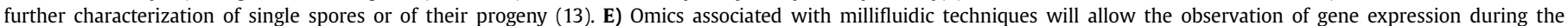

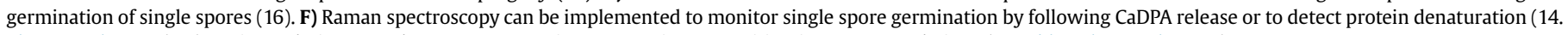
Zhang et al., 2009). G) Omics techniques analyze gene expression or protein composition in spore populations (15. Abhyankar et al., 2013).

differences of phenotypes compared to the wild strain and the potential instability of the transformation could limit the application of this method.

The methods described in this section 3 "Culture dependent methods and indirect measurements" do not allow direct observation of spores or biochemical analyses related to secreted or released cellular compounds. Moreover, the different cellular states cannot be distinguished and the differential quantification of dormant spores, germinated spores and vegetative cells is not possible. The next section will deal with methods of direct spore observation, such as microscopy and flow cytometry.

\section{Microscopy and flow cytometry methods (Fig. 2C-D)}

Microscopy and flow cytometry discriminate between different physiological stages of germination and outgrowth by spore optical properties (refractivity), morphology (spheroid vs rod), and/or physiological activity (enzymatic or respiratory activity, membrane permeability). Both methods are based on the direct observation of cells, which may be marked with detectable probes. Phase contrast microscopy differentiates dormant spores (phase-bright spores) from germinated spores (phase-dark) by their higher refractive index and from vegetative cells by their smaller size (Chen, Huang, \& Li, 2006; Hornstra, Ter Beek, Smelt, Kallemeijn, \& Brul, 2009; Tychinsky et al., 2007). Various physical media may be used for microscopic observation of spore germination and outgrowth. The spores can be deposited on a microscope slide, and then dried. The medium of germination (such as an L-alanine or inosine solution) and/or growth is either the suspension medium of the spores or is added after drying the slide (Kong, Doona, Setlow, \& Li, 2014). Spores may also be placed on a semi-solid medium (such as a $1 \%$ agarose gel) previously prepared on a microscope slide (Pandey \& Pieper et al., 2015; Pandey \& Ter Beek et al., 2015; Stringer et al. 2005; Webb, Stringer, Le Marc, Baranyi, \& Peck, 2012). Pandey and Pieper et al. (2015), Pandey and Ter Beek et al. (2015) also added a closed air-containing chamber made of an adhesive GeneFrame $^{\circledR}$ (primarily designed for in situ hybridization and amplification) to the slide. Spores have also been deposited on strips of 
Anopore ${ }^{\circledR}$ permeable membranes (den Besten et al., 2010). Time lapse image systems promote the acquisition of images at relatively high frequency, possibly of spores followed individually when placed on a medium (Fig. 2C). Image analysis is required to monitor the diverse cellular states. Phase-bright and phase-dark spores can be discriminated by their pixel intensity on spore images (Pandey et al., 2013; Pandey \& Pieper et al., 2015; Pandey \& Ter Beek et al., 2015; Stringer, Webb, \& Peck, 2009; Ter Beek et al., 2011; Webb et al., 2012). The different spores or cells can be enumerated and the size can be measured using dedicated software. For instance the SporeTracker software quantifies the decreasing pixel intensity during spore germination and the increasing area as the outgrowing cell size increases. SporeTracker can even detect the new cell popping out of the external spore layers, coat and exosporium; this event is called the "burst" (Pandey et al., 2013).

The time required to complete each step of the transformation of each cell within the population (germination, then outgrowth and first division) can be measured with these microscopical or flow cytometry techniques. Interestingly, the first spores to germinate are not the quickest to form a dividing cell, suggesting a rather time-independent pattern in the successive completion of germination and outgrowth events (Smelt, Stringer, \& Brul, 2013). The impact of sublethal heat treatment, environmental conditions (incubation temperature or $\mathrm{pH}$ ), or preservatives (tea antimicrobial compounds, sorbic acid for instance) on the times to completion of the spore transformations can be estimated and statistically analyzed (Pandey \& Pieper et al., 2015; Pandey \& Ter Beek et al., 2015). The influence of spore density and relative proximity on the germination of Clostridium botulinum spores has been demonstrated using these observation techniques. Practical experiments are performed on populations of several dozen to several thousands of cells, which gives some statistical and biological breadth to the observed phenomena (Pandey et al., 2013; Stringer et al., 2009).

Dynamic phase microscopy is performed with a laser phase microscope equipped with a He-Ne laser emitting at $633 \mathrm{~nm}$. Dynamic phase microscopy estimates phase thickness, i.e. the difference in the optical path (nm) according to the nature of the different structures. Bacterial spore phase thickness can be defined as the spatial distribution of optical path difference between interfering beams, which reflects the state of an object. This technique has shown some potential to study the activation of spores by heat, a sublethal treatment promoting the germination of many species of spore-forming bacteria. Dormant spores (refractive) and germinated spores of $B$. licheniformis had significantly different phase thickness values (Tichinsky, Kretushev, \& Luskinovich, 2006; Tychinsky et al., 2007). Moreover, heat inactivated spores had a lower phase thickness value than dormant spores. The phase thickness values of spores which had been heat-activated but placed in an environment unsuitable for germination revert to values of untreated spores, confirming the reversibility of the activation treatment shown by other techniques (Setlow, 2013). Epifluorescence microscopy can also provide opportunities to study spore germination, outgrowth and growth by detecting and interpreting the fluorescence signal emitted by fluorescent probes marking spore structural elements (Fig. 2C). Dormant spores are impermeable to many molecules. The outer layers (coat, outer membrane and cortex) are permeable to small molecules (from $2 \mathrm{kDa}$ to $8 \mathrm{kDa}$ ) (Driks, 1999; Henriques \& Moran., 2007). The first hurdle in staining a spore is its impermeability to larger molecules such as fluorescent dyes. Syto9 passes through intact membranes, intercalates DNA and emits a $540 \mathrm{~nm}$-wavelength light when excited at $488 \mathrm{~nm}$. Dormant spores hardly stain with Syto9, with only a green halo at the spore surface possibly due to mother cell DNA on the spore surface (Cronin \& Wilkinson, 2007). As the spore germinates and the core hydrates, Syto9 reaches spore DNA and germinated spores show a green fluorescence (Cronin \& Wilkinson, 2007; Reineke, Mathys, Heinz, \& Knorr, 2013). In addition to DNA probes, such as Syto9 or propidium iodide (PI), fluorescent markers such as CFDA may reveal perturbations of the membrane integrity and be applied to the study of spore metabolic activity recovery during outgrowth (Cronin \& Wilkinson, 2007). Nucleoid morphology can be analyzed by epifluorescence microscopy to monitor spore germination. The staining of nucleoids is not possible in dormant spores due to the impermeability of the structure, but germinated spores, as forespores, contain ringshaped nucleoids. The nucleoids of germinated spores are associated with $\alpha / \beta$ small acid-soluble proteins (SASPs), which seem to have a role in germination and outgrowth: B. subtilis $\alpha^{-}-\beta^{-}$SASP spores require a significantly longer time to recover a vegetative cell state (Ragkousi, Cowan, Ross, \& Setlow, 2000).

Transmission Electronic Microscopy (TEM) is based on the variation of electron transmission through biological material and is particularly well suited to the observation of multilayered structures, which bacterial spores are, and more specifically to the evolution of spore structures during germination and outgrowth (Dey, Hoffman, \& Glomski, 2012; Saif Zaman et al., 2005). The phenomenon called "bottle cap" that consists in the opening of a precise region of the spore exosporium leading to the escape of the new vegetative cell has thus been observed in Clostridium sporogenes spores (Brunt, Cross, \& Peck, 2015). The "bottle cap" phenomenon may not be so different of the "burst" observed with B. subtilis spores by phase contrast microscopy (Pandey et al., 2013). The aperture allowing the cell to escape from external spore layers has also been observed by scanning electron microscopy (SEM) (Bassi, Cappa, \& Cocconcelli, 2009; Brunt et al., 2015; Steichen, Kearney, \& Turnbough, 2007). This method, in contrast to TEM, allows the observation of entire spores (versus a cross-section with TEM). These two methods are complementary for the analysis of spore structure evolution during germination and outgrowth. Atomic Force Microscopy generates images from the signal variations emitted by a mechanical probe displaced at a nanoscale on the surface of the "observed" object. Only changes in external layers of the spores can therefore be detected. Nevertheless, this method has successfully revealed alterations in coat architecture and topology during germination or after heat treatment (Pinzón-Arango, Scholl, Nagarajan, Mello, \& Camesano, 2009; Plomp, Leighton, Wheeler, Hill, \& Malkin, 2007; Tabit \& Buys, 2010). TEM, SEM and AFM are destructive, with some possible artifacts due to harsh sample preparation conditions. Electron cryotomography (ECT) is also destructive, but objects are preserved in a near-native state thanks to ultra-quick freezing. Multi-directional EM images are computerized to give reconstructed 3-D images (Tocheva, Li, \& Jensen, 2010). Peptidoglycan rearrangements and cortex thickening and thinning have thus been monitored throughout sporulation, spore maturation, and outgrowth of B. subtilis (Tocheva et al., 2013). However, as with TEM, SEM and AFM, the number of cells that can reasonably be observed and analyzed is inversely correlated to the structural details that can be revealed. These images are priceless for basic studies, but of rather poor utility for population studies with statistical significance or for the acquisition of large quantities of data.

With flow cytometry, spores or cells are aligned along a liquid flow in a capillary and detected with a laser beam. The light signals are analyzed by computing. The forward scattered (FSC) light signal provides information on cell size and the side-scattered light signal on cell inner structure or complexity. In addition appropriate fluorescent probes, commonly the same as those used in fluorescent microscopy, may provide information on cell permeability, viability or metabolic activity. Flow cytometry can be used to monitor germination, outgrowth and growth. Germinated spores 
differ from dormant spores due to their higher probe fluorescence (of Syto9 for instance) generated by the permeation of spore layers and core hydration during germination (van Melis, Nierop Groot, Tempelaars, Moezelaar, \& Abee, 2011). Spheroidal germinated spores and rod-shaped vegetative cells differ in size. Several characteristics can be obtained for each single cell in one pass through the detector, with size and fluorescence simultaneously providing information on the morphological or physiological states of the evolving spore populations. Other characteristics can be obtained with additional specific detectors (Mathys, Chapman, Bull, Heinz, \& Knorr, 2007; van Melis et al. 2011). In contrast to phase contrast microscopy, the monitoring of a single cell over time is rather limited, but the number of cells that can be observed and characterized can be substantially higher (several tens of thousands of events is not uncommon). Flow cytometry has been used for instance to estimate the impact of high pressure (HP), heat treatments, or sorbic acid on Bacillus cereus or Bacillus licheniformis spore survival, germination and outgrowth (Cronin \& Wilkinson, 2007, 2008; Mathys et al., 2007; Reineke et al., 2013; van Melis et al., 2011).

\section{Molecular methods (Fig. 2E-F-G)}

Molecular methods used for monitoring spore germination, outgrowth and growth can be presented as destructive or nondestructive methods performed on spore populations, spore population extracts or on specific components. Some methods can be implemented at single cell level.

As in any other biological process, the spore germination, outgrowth and growth process is increasingly analyzed with 'omic' technologies. Genomics, transcriptomics and proteomics establish a link between the spore behavior under different stresses and the fundamental basis of this behavior (Abhyankar et al., 2016). The socalled 'omics' data are increasingly used as new tools for hazard identification and characterization, as well as for exposure assessment. These 'omics' data may provide a better understanding of the diversity of physiological states and thus lead to the identification of biomarkers, such as specific genes or specific proteins for example, that may be used as quantitative data to build predictive models applied to Microbial Risk Assessment (Brul et al., 2012; McMeekin, Hill, Wagner, Dahl, \& Ross, 2010; Membré \& Guillou, 2016). Transcriptomic analysis requires gene expression and mRNA synthesis, which are not essential in the earliest germination events (Korza, Setlow, Rao, Li, \& Setlow, 2017). However, transcriptomic analyses are well suited to studying what happens in lag or early growth from bacterial spores. RNA extraction from spores requires some attention because of the particular structure of spores (Moeller et al., 2006) (Fig. 2G). RNA is extracted from germinated spores or outgrowing cells over time and analyzed using different methods such as microarrays (Keijser et al., 2007), RNA-seq (Nagler et al., 2016) or RT qPCR (Bassi et al., 2016). Gene expression can be analyzed by specific pipelines such as T-Rex or JBrowse (Skinner, Uzilov, Stein, Mungall, \& Holmes, 2009; de Jong, van der Meulen, Kuipers, \& Kok, 2015). Thus, the evolution of cellular activity can be followed during germination and outgrowth and the impact of the incubation environment on this activity can be observed. For example, spore transcripts decrease during germination and early outgrowth until they are undetectable as the RNA stored in the spores is used as a source for de novo RNA and an initial source of nucleotides (Keijser et al., 2007). The impact of salinity on Bacillus subtilis has been investigated by a transcriptomic approach revealing a significant impact on stress gene expression during outgrowth (Nagler et al., 2016). Proteins have a major role in structure and protection, such as coat proteins, and in differentiation from germinant receptors or cortex lytic enzymes (Setlow,
2014). Proteomic methods can be applied in order to study germination and outgrowth (Fig. 2G). The extracted proteins are digested and analyzed by liquid chromatography associated with mass spectrometry (Abhyankar et al., 2011, 2014; Brul et al., 2011). Several proteins are essential for early germination steps: the germinant receptors, DPA channel proteins, cortex lytic enzymes (CLEs) and lipoproteins that are potentially implicated in the transduction of the germinant binding (Setlow, 2003, 2014). Analyzing dormant spores, germinated spores and outgrowing cells reveal an evolution of their proteome during germination and outgrowth process. For example, YpeB is 14 -fold less detected in germinated spores than in dormant spores. YpeB is required for the incorporation of the CLE SleB in the inner spore membrane during sporulation, and then for its degradation during germination (Chen, Ray, Helm, Melville, \& Popham, 2014). The changes in spore proteome over time can be monitored during the germination and outgrowth process. A set of proteins appeared to be significantly reduced during the germination step (Jagtap et al., 2006). The 'omics' methods are destructive and still applicable only to large spore populations $\left(>10^{7}\right.$ spores $\left.\mathrm{mL}^{-1}\right)$. According to recent works, single cell 'omics' analyses are crucial to be able to take into account the heterogeneity of a spore population (Abhyankar, Stelder, de Koning, de Koster, \& Brul, 2017; Blainey, 2013).

Remarkable details of spore germination at individual cell levels have been obtained with Raman spectroscopy (Fig. 2F). Raman spectroscopy is based on the excitation of molecules by a laser. Each spore or cell in this case is considered as a molecular mix. The emitted radiation is collected by a detector and the variation of emitted energy provides information on the energetic levels of the molecules composing the spore or the cell. This method, in combination with confocal microscopy, Raman spectrometry and laser tweezers (exploiting the dielectric properties of cells for separation) have been used to monitor the germination of single spores. CaDPA Raman spectra bands can be identified in several species of spore-forming bacteria such as Geobacillus stearothermophilus, B. subtilis or B. thuringiensis (Chen et al., 2006; Gelder et al., 2007; Zhou, Dong, Setlow, \& Li, 2013). The disappearance of the CaDPA spectral bands indicates the CaDPA release from the spore core and has been used to follow the germination of $B$. subtilis or G. stearothermophilus spores, for instance (Chen et al., 2006; Vepachedu \& Setlow, 2004; Wang, Zhang, Setlow, \& Li, 2011, 2015; Zhang, Setlow, \& Li, 2009; Zhou et al., 2013). Moreover, the comparison of Raman spectra of dormant spores, germinated spores and heat-treated spores has shown that wet heat treatment causes spore protein denaturation, and hence inhibits germination (Zhang et al., 2009). Spore germination can also be followed through the release of DPA with X-Ray analysis. Electrons from an external source strike the spore atoms, leading to energy emission as X-Ray photons with X-Ray characteristics of the element (Bassi et al., 2009). CaDPA can also be detected by mass spectrometry or Fourier Transform Infrared Spectroscopy (FTIR) and can even be a biomarker of the presence of bacterial spores (Goodacre et al., 2000).

Millifluidic or microfluidic technologies could be employed in order to monitor spore germination, outgrowth and growth. These methods are emerging in microbiology and a device has been specifically developed to study Bacillus subtilis spore germination and outgrowth. This device is based on the changes in electrical conductivity of a polyaniline nanofiber network. Electrical changes are induced by the spores passing through a measuring interface and the signal depends on the state of the cell (dormant spores, germinated spores or vegetative cells) (Zabrocka, Langer, Michalski, Kocik, \& Langer, 2015). 


\section{Conclusion}

Many techniques and methods can be implemented to monitor the germination, outgrowth and growth process. They operate at different scales, from cellular to molecular, and on different number of studied cells, from a whole population to single spores. It is worth noting that all these methods are complementary: some provide better knowledge of the biological process while others quantitatively determine the impact of different factors, such as heat treatment or incubation $\mathrm{pH}$, on the spores' ability to complete germination, outgrowth and growth.

The ideal method, which does not yet exist, would give quantitative molecular information from the single cell level to the cell population level. By combining different methods, such as 'omics' allied to microfluidics, results can be obtained at both cellular and molecular levels. Such methods are emerging, like mass cytometry, derived from mass spectrometry and applied to analyses of individual cells. At the time of writing, this method is available mainly for mammalian cells, as other techniques like flow cytometry for example were. It is expected to be extended and adapted to microorganisms as mass cytometry has been used to discriminate different strains of $E$. coli (Leipold, Ornatsky, Baranov, Whitfield, \& Nitz, 2011). We can expect an extension of this method to single bacterial spores, targeting specific spore molecules such as CaDPA. Moreover, advances in microfluidic methods, like the Droplet PCR technique used to study genomes at single cell level (GutiérrezAguirre, Rački, Dreo, \& Ravnikar, 2015; Ottesen, Hong, Quake, \& Leadbetter, 2006), offer novel approaches and new opportunities to develop methods allowing gene expression analysis or the proteome study of single spores. The behavior of spores in a food matrix can be different from the behavior observed in laboratory media. Thus, the impact of the food matrix has to be taken into account to improve the control of spore-forming bacteria in foods (Warda, den Besten, Sha, Abee, \& Nierop Groot, 2015). Clearly, not all the methods we have described in this review can be applied to study spore behavior in a food matrix. Generally, food-based media are developed to mimic the food matrices and culture-dependent methods or, more recently, microscopy and transcriptomic methods have been used to study spore germination and outgrowth (Bassi et al., 2016; Warda et al., 2015). The study of germination, outgrowth and growth, as well as the impact of environmental factors on this process, by methods at different scales provides better comprehension of these phenomena leading to better control of the behavior of spore-forming bacteria.

\section{Acknowledgements}

This work is a partial fulfilment of Clément Trunet's PhD thesis and was supported by the Conseil Régional de Bretagne under the Spore'Up contract, by ADRIA Développement (Quimper, France), and by Bretagne Biotechnologie Alimentaire (Rennes, France) and the French National Association of Technical Research (ANRT, Paris) (0801/2012). The authors wish to thank the reviewers of their manuscript for their absolutely relevant comments and useful recommendations to improve both substance and form, and Noémie Desriac for her critical reading of the manuscript.

\section{References}

Abee, T., Groot, M., Tempelaars, M., Zwietering, M., Moezelaar, R., \& Voort, M. (2011) Germination and outgrowth of spores of Bacillus cereus group members: Diversity and role of germinant receptors. Food Microbiology, 28(2), 199-208.

Abhyankar, W., Hossain, A. H., Djajasaputra, A., Permpoonpattana, P., Ter Beek, A. Dekker, H. L., Cutting, S. M., Brul, S., de Koning, L. J., \& de Koster, C. G. (2013). In pursuit of protein targets: Proteomic characterization of bacterial spore outer layers. Journal of Proteome Research, 12, 4507-4521.
Abhyankar, W., de Koning, L., Brul, S., \& de Koster, C. (2014). Spore proteomics: The past, present and the future. FEMS Microbiology Letters, 358(2), 137-144.

Abhyankar, W., Kamphorst, K., Swarge, B., van Veen, H., van der Wel, N., Brul, S., et al. (2016). The influence of sporulation conditions on the spore coat protein composition of Bacillus subtilis spores. Microbial Physiology and Metabolism, 1636.

Abhyankar, W., Stelder, S., de Koning, L., de Koster, C., \& Brul, S. (2017). “Omics” for microbial food stability: Proteomics for the development of predictive models for bacterial spore stress survival and outgrowth. International Journal of Food Microbiology, 240, 11-18.

Abhyankar, W., Ter Beek, A., Dekker, H., Kort, R., Brul, S., \& de Koster, C. (2011). Gelfree proteomic identification of the Bacillus subtilis insoluble spore coat protein fraction. Proteomics, 11(23), 4541-4550.

Baril, E., Coroller, L., Couvert, O., Leguérinel, I., Postollec, F., Boulais, C., et al. (2012) Modeling heat resistance of Bacillus weihenstephanensis and Bacillus licheniformis spores as function of sporulation temperature and pH. Food Microbiology, 30, 29-36.

Bassi, D., Cappa, F., \& Cocconcelli, P. S. (2009). A combination of a SEM technique and X-ray microanalysis for studying the spore germination process of Clostridium tyrobutyricum. Research in Microbiology, 160(5), 322-329.

Bassi, D., Colla, F., Gazzola, S., Puglisi, E., Delledonne, M., \& Cocconcelli, P. (2016) Transcriptome analysis of Bacillus thuringiensis spore life, germination and cell outgrowth in a vegetable-based food model. Food Microbiology, 55, 73-85.

den Besten, H., Arvind, A., Gaballo, H., Moezelaar, R., Zwietering, M., \& Abee, T. (2010). Short- and long-term biomarkers for bacterial robustness: A framework for quantifying correlations between cellular indicators and adaptive behavior. PLoS One, 5(10)

Blainey, P. C. (2013). The future is now: Single-cell genomics of bacteria and archaea FEMS Microbiology Reviews, 37(3), 407-427.

Brul, S., Bassett, J., Cook, P., Kathariou, S., McClure, P., Jasti, P., et al. (2012). "Omics" technologies in quantitative microbial risk assessment. Trends in Food Science \& Technology, 27(1), 12-24.

Brul, S., van Beilen, J., Caspers, M., O'Brien, A., de Koster, C., Oomes, S., et al. (2011). Challenges and advances in systems biology analysis of Bacillus spore physiology; molecular differences between an extreme heat resistant spore forming Bacillus subtilis food isolate and a laboratory strain. Food Microbiology, 28(2), 221-227.

Bruno, J. G. (2014). An Acridine orange spore germination fluorescence microscopy versus spectral paradox. Journal of Fluorescence, 1-6.

Brunt, J., Cross, K., \& Peck, M. (2015). Apertures in the Clostridium sporogenes spore coat and exosporium align to facilitate emergence of the vegetative cell. Food Microbiology, 51, 45-50.

Chastanet, A., Vitkup, D., Yuan, G.-C., Norman, T., Liu, J., \& Losick, R. (2010). Broadly heterogeneous activation of the master regulator for sporulation in Bacillus subtilis. Proceedings of the National Academy of Sciences of the United States of America, 107(18), 8486-8491.

Chen, D., Huang, S., \& Li, Y. (2006). Real-time detection of kinetic germination and heterogeneity of single Bacillus spores by laser tweezers Raman spectroscopy. Analytical Chemistry, 78(19), 6936-6941.

Chen, Y., Ray, W., Helm, R., Melville, S., \& Popham, D. (2014). Levels of germination proteins in Bacillus subtilis dormant, superdormant, and germinating spores. PLOS One, 9(4), e95781.

Ciarciaglini, G., Hill, P. J., Davies, K., McClure, P. J., Kilsby, D., Brown, M., et al. (2000). Germination-induced bioluminescence, a route to determine the inhibitory effect of a combination preservation treatment on bacterial spores. Applied and Environmental Microbiology, 66(9), 3735-3742.

Collado, J., Fernández, A., Rodrigo, M., Camats, J., \& Lopez, A. (2003). Kinetics of deactivation of Bacillus cereus spores. Food Microbiology, 20(5), 545-548.

Cronin, U., \& Wilkinson, M. (2007). The use of flow cytometry to study the germination of Bacillus cereus endospores. Cytometry A, 71A(3), 143-153.

Cronin, U. P., \& Wilkinson, M. (2008). Bacillus cereus endospores exhibit a heterogeneous response to heat treatment and low-temperature storage. Food Microbiology, 25(2), 235-243.

Daelman, J., Sharma, A., Vermeulen, A., Uyttendaele, M., Devlieghere, F., \& Membré, J.-M. (2013). Development of a time-to-detect growth model for heattreated Bacillus cereus spores. International Journal of Food Microbiology, 165(3), $231-240$

Dey, R., Hoffman, P., \& Glomski, I. (2012). Germination and amplification of anthrax spores by soil-dwelling amoebas. Applied and Environmental Microbiology. 78(22), 8075-8081.

Driks, A. (1999). Bacillus subtilis spore coat. Microbiology and Molecular Biology Reviews, 63(1), 1-20.

Gaillard, S., Leguérinel, I., Savy, N., \& Mafart, P. (2005). Quantifying the combined effects of the heating time, the temperature and the recovery medium $\mathrm{pH}$ on the regrowth lag time of Bacillus cereus spores after a heat treatment. International Journal of Food Microbiology, 105(1), 53-58.

Garcia, D., van der Voort, M., \& Abee, T. (2010). Comparative analysis of Bacillus weihenstephanensis KBAB4 spores obtained at different temperatures. International Journal of Food Microbiology, 140(2-3), 146-153.

Gelder, J. D., Scheldeman, P., Leus, K., Heyndrickx, M., Vandenabeele, P., Moens, L., \& Vos, P. D. (2007). Raman spectroscopic study of bacterial endospores. Analytical and Bioanalytical Chemistry, 389, 2143-2151.

Goodacre, R., Shann, B., Gilbert, R. J., Timmins, E. M., McGovern, A., Alsberg, B., et al. (2000). Detection of the dipicolinic acid biomarker in Bacillus spores using Curie-point pyrolysis mass spectrometry and Fourier transform infrared 
spectroscopy. Analytical Chemistry, 72(1), 119-127.

Gutiérrez-Aguirre, I., Rački, N., Dreo, T., \& Ravnikar, M. (2015). Droplet Digital PCR for absolute quantification of pathogens. In C. Lacomme (Ed.), Plant pathology (pp. 331-347). New York: Springer.

Henriques, A., \& Moran, C. (2007). Structure, assembly, and function of the spore surface layers. Annual Review of Microbiology, 61(1), 555-588.

Hill, P., Hall, L., Vinicombe, D., Soper, C., Setlow, P., Waites, W., et al. (1994). Bioluminescence and spores as biological indicators of inimical processes. Journal of Applied Bacteriology, 76, 129S-134S.

Hornstra, L., de Vries, Y., Wells-Bennik, M. H. J., de Vos, W., \& Abee, T. (2006). Characterization of germination receptors of Bacillus cereus ATCC 14579. Applied and Environmental Microbiology, 72(1), 44-53.

Hornstra, L., Ter Beek, A., Smelt, J., Kallemeijn, W., \& Brul, S. (2009). On the origin of heterogeneity in (preservation) resistance of Bacillus spores: Input for a "systems" analysis approach of bacterial spore outgrowth. International Journal of Food Microbiology, 134(1-2), 9-15.

Jagtap, P., Michailidis, G., Zielke, R., Walker, A. K., Patel, N., Strahler, J. R., et al. (2006). Early events of Bacillus anthracis germination identified by time-course quantitative proteomics. Proteomics, 6(19), 5199-5211.

de Jong, A., van der Meulen, S., Kuipers, O. P., \& Kok, J. (2015). T-REx: Transcriptome analysis webserver for RNA-seq expression data. BMC Genomics, 16, 663.

Keijser, B., Ter Beek, A., Rauwerda, H., Schuren, F., Montijn, R., van der Spek, H., et al. (2007). Analysis of temporal gene expression during Bacillus subtilis spore germination and outgrowth. Journal of Bacteriology, 189(9), 3624-3634.

Kong, L., Doona, C., Setlow, P., \& Li, Y. (2014). Monitoring rates and heterogeneity of high-pressure germination of Bacillus spores by phase-contrast microscopy of individual spores. Applied and Environmental Microbiology, 80(1), 345-353.

Kort, R., O'Brien, A., van Stokkum, I., Oomes, S., Crielaard, W., Hellingwerf, K., et al. (2005). Assessment of heat resistance of bacterial spores from food product isolates by fluorescence monitoring of dipicolinic acid release. Applied and Environmental Microbiology, 71(7), 3556-3564.

Korza, G., Setlow, B., Rao, L., Li, Q., \& Setlow, P. (2017). Changes in Bacillus spore small molecules, rRNA, germination and outgrowth after extended sub-lethal exposure to various temperatures: Evidence that protein synthesis is not essential for spore germination. Journal of Bacteriology, 199(9). JB.00583-16.

Leguerinel, I., Couvert, O., \& Mafart, P. (2000). Relationship between the apparent heat resistance of Bacillus cereus spores and the $\mathrm{pH}$ and $\mathrm{NaCl}$ concentration of the recovery medium. International Journal of Food Microbiology, 55(1-3), $223-227$.

Leguérinel, I., Couvert, O., \& Mafart, P. (2006). Modelling the influence of the incubation temperature upon the estimated heat resistance of heated Bacillus spores. Letters in Applied Microbiology, 43(1), 17-21.

Leipold, M. D., Ornatsky, O., Baranov, V., Whitfield, C., \& Nitz, M. (2011). Development of mass cytometry methods for bacterial discrimination. Analytical Biochemistry, 419(1), 1-8.

Mafart, P., \& Leguérinel, I. (1998). Modeling combined effects of temperature and pH on heat resistance of spores by a linear-Bigelow equation. Journal of Food Science, 63(1), 6-8.

Mallozzi, M., Viswanathan, V., \& Vedantam, G. (2010). Spore-forming Bacilli and Clostridia in human disease. Future Microbiology, 5(7), 1109-1123.

Mathys, A., Chapman, B., Bull, M., Heinz, V., \& Knorr, D. (2007). Flow cytometric assessment of Bacillus spore response to high pressure and heat. Innovative Food Science \& Emerging Technologies, 8(4), 519-527.

McMeekin, T., Hill, C., Wagner, M., Dahl, A., \& Ross, T. (2010). Ecophysiology of foodborne pathogens: Essential knowledge to improve food safety. International Journal of Food Microbiology, 139, S64-S78.

van Melis, C., Almeida, C., Kort, R., Groot, M., \& Abee, T. (2012). Germination inhibition of Bacillus cereus spores: Impact of the lipophilic character of inhibiting compounds. International Journal of Food Microbiology, 160(2), 124-130.

van Melis, C. C. J., den Besten, H. M. W., Nierop Groot, M. N., \& Abee, T. (2014) Quantification of the impact of single and multiple mild stresses on outgrowth heterogeneity of Bacillus cereus spores. International Journal of Food Microbiology, 177, 57-62.

van Melis, C., Nierop Groot, M., Tempelaars, M., Moezelaar, R., \& Abee, T. (2011) Characterization of germination and outgrowth of sorbic acid-stressed Bacillus cereus ATCC 14579 spores: Phenotype and transcriptome analysis. Food Microbiology, 28(2), 275-283.

Membré, J.-M., \& Guillou, S. (2016). Latest developments in foodborne pathogen risk assessment. Current Opinion in Food Science, 8, 120-126.

Moeller, R., Horneck, G., Rettberg, P., Mollenkopf, H.-J., Stackebrandt, E., \& Nicholson, W. L. (2006). A method for extracting RNA from dormant and germinating Bacillus subtilis strain 168 endospores. Current Microbiology, 53(3), 227-231.

Mtimet, N., Trunet, C., Mathot, A.-G., Venaille, L., Leguérinel, I., Coroller, L., et al (2015). Modeling the behavior of Geobacillus stearothermophilus ATCC 12980 throughout its life cycle as vegetative cells or spores using growth boundaries. Food Microbiology, 48, 153-162.

Nagler, K., Krawczyk, A., De Jong, A., Madela, K., Hoffmann, T., Laue, M., et al. (2016). Identification of differentially expressed genes during Bacillus subtilis spore outgrowth in high-salinity environments using RNA sequencing. Frontiers in Microbiology, 7.

Ottesen, E., Hong, J., Quake, S., \& Leadbetter, J. (2006). Microfluidic Digital PCR enables multigene analysis of individual environmental bacteria. Science, 314(5804), 1464-1467.

Paidhungat, M., Setlow, B., Daniels, W., Hoover, D., Papafragkou, E., \& Setlow, P.
(2002). Mechanisms of induction of germination of Bacillus subtilis spores by high pressure. Applied and Environmental Microbiology, 68(6), 3172-3175.

Pandey, R., Pieper, G., Ter Beek, A., Vischer, N., Smelt, J., Manders, E., et al. (2015a). Quantifying the effect of sorbic acid, heat and combination of both on germination and outgrowth of Bacillus subtilis spores at single cell resolution. Food Microbiology, 52, 88-96.

Pandey, R., Ter Beek, A., Vischer, N., Smelt, J., Brul, S., \& Manders, E. (2013). Live cell imaging of germination and outgrowth of individual Bacillus subtilis spores; the effect of heat stress quantitatively analyzed with SporeTracker. PLoS One, 8(3), e58972.

Pandey, R., Ter Beek, A., Vischer, N., Smelt, J., Kemperman, R., Manders, E., et al. (2015b). Quantitative analysis of the effect of specific tea compounds on germination and outgrowth of Bacillus subtilis spores at single cell resolution. Food Microbiology, 45, 63-70.

Pinzón-Arango, P., Scholl, G., Nagarajan, R., Mello, C., \& Camesano, T. (2009). Atomic force microscopy study of germination and killing of Bacillus atrophaeus spores. Journal of Molecular Recognition, 22(5), 373-379.

Plomp, M., Leighton, T., Wheeler, K., Hill, H., \& Malkin, A. (2007). In vitro highresolution structural dynamics of single germinating bacterial spores. Proceedings of the National Academy of Sciences, 104(23), 9644-9649.

Ragkousi, K., Cowan, A., Ross, M., \& Setlow, P. (2000). Analysis of nucleoid morphology during germination and outgrowth of spores of Bacillus species, Journal of Bacteriology, 182(19), 5556-5562.

Reineke, K., Mathys, A., Heinz, V., \& Knorr, D. (2013). Mechanisms of endospore inactivation under high pressure. Trends in Microbiology, 21(6), 296-304.

Roubos-van den Hil, P., Dalmas, E., Nout, M., \& Abee, T. (2010). Soya bean tempe extracts show antibacterial activity against Bacillus cereus cells and spores. Journal of Applied Microbiology, 109(1), 137-145.

Saif Zaman, M., Goyal, A., Prakash Dubey, G., Gupta, P., Chandra, H., Das, T., et al. (2005). Imaging and analysis of Bacillus anthracis spore germination. Microscopy Research and Technique, 66(6), 307-311.

Segev, E., Rosenberg, A., Mamou, G., Sinai, L., \& Ben-Yehuda, S. (2013). Molecular kinetics of reviving bacterial spores. Journal of Bacteriology, 195(9), 1875-1882.

Setlow, P. (2003). Spore germination. Current Opinion in Microbiology, 6(6), $550-556$

Setlow, P. (2012). Dynamics of the assembly of a complex macromolecular structure the coat of spores of the bacterium Bacillus subtilis: B. subtilis spore coat. Molecular Microbiology, 83(2), 241-244.

Setlow, P. (2013). Summer meeting 2013 - when the sleepers wake: The germination of spores of Bacillus species. Journal of Applied Microbiology, 115(6), $1251-1268$.

Setlow, P. (2014). Germination of spores of Bacillus species: What we know and do not know. Journal of Bacteriology, 196(7), 1297-1305.

Setlow, B., Melly, E., \& Setlow, P. (2001). Properties of spores of Bacillus subtilis blocked at an intermediate stage in spore germination. Journal of Bacteriology, 183(16), 4894-4899.

Skinner, M., Uzilov, A., Stein, L., Mungall, C., \& Holmes, I. (2009). JBrowse: A nextgeneration genome browser. Genome Research, 19(9), 1630-1638.

Smelt, J., Bos, A., Kort, R., \& Brul, S. (2008). Modelling the effect of sub(lethal) heat treatment of Bacillus subtilis spores on germination rate and outgrowth to exponentially growing vegetative cells. International Journal of Food Microbiology, 128(1), 34-40.

Smelt, J., Stringer, S., \& Brul, S. (2013). Behaviour of individual spores of non proteolytic Clostridium botulinum as an element in quantitative risk assessment. Food Control, 29(2), 358-363.

Steichen, C., Kearney, J., \& Turnbough, C. (2007). Non-uniform assembly of the Bacillus anthracis exosporium and a bottle cap model for spore germination and outgrowth: Non-uniform assembly of the B. anthracis exosporium. Molecular Microbiology, 64(2), 359-367.

Stringer, S., Webb, M., George, S., Pin, C., \& Peck, M. (2005). Heterogeneity of times required for germination and outgrowth from single spores of nonproteolytic Clostridium botulinum. Applied and Environmental Microbiology, 71(9), 4998-5003.

Stringer, S., Webb, M., \& Peck, M. (2009). Contrasting effects of heat treatment and incubation temperature on germination and outgrowth of individual spores of nonproteolytic Clostridium botulinum bacteria. Applied and Environmental Microbiology, 75(9), 2712-2719.

Stringer, S., Webb, M., \& Peck, M. (2011). Lag time variability in individual spores of Clostridium botulinum. Food Microbiology, 28(2), 228-235.

Sunde, E., Setlow, P., Hederstedt, L., \& Halle, B. (2009). The physical state of water in bacterial spores. Proceedings of the National Academy of Sciences, 106(46), 19334-19339.

Tabit, F., \& Buys, E. (2010). The effects of wet heat treatment on the structural and chemical components of Bacillus sporothermodurans spores. International Journal of Food Microbiology, 140(2-3), 207-213.

Ter Beek, A., Hornstra, L. M., Pandey, R., Kallemeijn, W. W., Smelt, J., Manders, E., et al. (2011). Models of the behaviour of (thermally stressed) microbial spores in foods: Tools to study mechanisms of damage and repair. Food Microbiology, 28(4), 678-684

Tichinsky, V., Kretushev, A., \& Luskinovich, P. (2006). Dynamic phase microscopy: Measurements of translational displacements at sub-nanometer scale. arXiv Preprint Physics/0608093.

Tocheva, E., Li, Z., \& Jensen, G. (2010). Electron cryotomography. Cold Spring Harbor Perspectives in Biology, 2(6).

Tocheva, E., López-Garrido, J., Hughes, H., Fredlund, J., Kuru, E., VanNieuwenhze, M., 
Version définitive du manuscrit publiée dans / Final version of the manuscript published in :

Trends in Food Science \& Technology (2017), Vol. 64, p. 60-68, DOI: 10.1016/j.tifs.2017.03.008

Journal homepage : http://www.journals.elsevier.com/locate/trends-in-food-science-and-technology

et al. (2013). Peptidoglycan transformations during Bacillus subtilis sporulation. Molecular Microbiology, 88(4), 673-686.

Trunet, C., Mtimet, N., Mathot, A.-G., Postollec, F., Leguerinel, I., Sohier, D., et al. (2015). Modeling the recovery of heat-treated Bacillus licheniformis Ad978 and Bacillus weihenstephanensis KBAB4 spores at suboptimal temperature and ph using growth limits. Applied and Environmental Microbiology, 81(2), 562-568.

Tychinsky, V., Mulyukin, A., Lisovskii, V., Nikolaev, Y., Kretushev, A., Vyshenskaya, T., et al. (2007). Dynamic phase microscopy, a new method to detect viable and killed spores and to estimate the heterogeneity of spore populations. Advances in Space Research, 40(11), 1678-1685.

Vepachedu, V., \& Setlow, P. (2004). Analysis of the germination of spores of Bacillus subtilis with temperature sensitive spo mutations in the spoVA operon. FEMS Microbiology Letters, 239(1), 71-77.

Wang, S., Setlow, P., \& Li, Y. (2015). Slow leakage of ca-dipicolinic acid from individual Bacillus spores during initiation of spore germination. Journal of Bacteriology, 197(6), 1095-1103.

Wang, G., Zhang, P., Setlow, P., \& Li, Y. (2011). Kinetics of germination of wet-heattreated individual spores of Bacillus species, monitored by Raman spectroscopy and differential interference contrast microscopy. Applied and Environmental Microbiology, 77(10), 3368-3379.

Warda, A., den Besten, H., Sha, N., Abee, T., \& Nierop Groot, M. (2015). Influence of food matrix on outgrowth heterogeneity of heat damaged Bacillus cereus spores. International Journal of Food Microbiology, 201, 27-34.

Webb, M., Stringer, S., Le Marc, Y., Baranyi, J., \& Peck, M. (2012). Does proximity to neighbours affect germination of spores of non-proteolytic Clostridium botulinum? Food Microbiology, 32(1), 104-109.

Wells-Bennik, M., Eijlander, R., den Besten, H., Berendsen, E., Warda, A., Krawczyk, A., et al. (2016). Bacterial spores in food: Survival, emergence, and outgrowth. Annual Review of Food Science and Technology, 7, 457-482.

Yi, X., \& Setlow, P. (2010). Studies of the commitment step in the germination of spores of Bacillus species. Journal of Bacteriology, 192(13), 3424-3433.

Zabrocka, L., Langer, K., Michalski, A., Kocik, J., \& Langer, J. (2015). A microfluidic device for real-time monitoring of Bacillus subtilis bacterial spores during germination based on non-specific physicochemical interactions on the nanoscale level. Lab on a Chip, 15(1), 274-282.

Zhang, P., Liang, J., Yi, X., Setlow, P., \& Li, Y.-q. (2014). Monitoring of commitment blocking, and continuation of nutrient germination of individual Bacillus subtilis spores. Journal of Bacteriology, 196, 2443-2454.

Zhang, P., Setlow, P., \& Li, Y. (2009). Characterization of single heat-activated Bacillus spores using laser tweezers Raman spectroscopy. Optics Express, 17(19), $16480-16491$.

Zhang, P., Thomas, S., Li, Y., \& Setlow, P. (2012). Effects of cortex peptidoglycan structure and cortex hydrolysis on the kinetics of $\mathrm{Ca}^{2+}$-dipicolinic acid release during Bacillus subtilis spore germination. Journal of Bacteriology, 194(3), 646-652.

Zhou, T., Dong, Z., Setlow, P., \& Li, Y. (2013). Kinetics of germination of individual spores of Geobacillus stearothermophilus as measured by Raman spectroscopy and differential interference contrast microscopy. PLoS One, 8(9). 